\title{
Using Grazing to Manage Herbaceous Structure for a Heterogeneity-Dependent Bird
}

JOHN D. KRAFT, Kansas Cooperative Fish and Wildlife Research Unit, Division of Biology, Kansas State University, Manhattan, KS 66506, USA DAVID A. HAUKOS, ${ }^{1}$ U.S. Geological Survey, Kansas Cooperative Fish and Wildife Research Unit, Kansas State University, Manhattan, KS 66506, USA

MATTHEW R. BAIN, Kansas Chapter of The Nature Conservancy, Smoky Valley Ranch, Oakley, KS 67748, USA

MINDY B. RICE, U.S. Fish and Wildlife Service, National Wildlife Refuge System, Fort Collins, CO 80525, USA

SAMANTHA ROBINSON, ${ }^{2}$ Kansas Cooperative Fish and Wildlife Research Unit, Division of Biology, Kansas State University, Manhattan, KS 66506, USA

DAN S. SULLINS, ${ }^{3}$ Kansas Cooperative Fish and Wildife Research Unit, Division of Biology, Kansas State University, Manhattan, KS 66506, USA CHRISTIAN A. HAGEN, Department of Fisheries and Wildlife, Oregon State University, Bend, OR 97702, USA

JAMES PITMAN, ${ }^{4}$ Conservation Delivery Director, Western Association of Fish and Wildlife Agencies, Emporia, KS 66801, USA

JOSEPH LAUTENBACH, ${ }^{5}$ Kansas Cooperative Fish and Wildlife Research Unit, Division of Biology, Kansas State University, Manhattan, KS 66506, USA

REID PLUMB, ${ }^{6}$ Kansas Cooperative Fish and Wildlife Research Unit, Division of Biology, Kansas State University, Manhattan, KS 66506, USA JONATHAN LAUTENBACH, ${ }^{7}$ Kansas Cooperative Fish and Wildlife Research Unit, Division of Biology, Kansas State University, Manhattan, KS 66506, USA

\begin{abstract}
Grazing management recommendations often sacrifice the intrinsic heterogeneity of grasslands by prescribing uniform grazing distributions through smaller pastures, increased stocking densities, and reduced grazing periods. The lack of patch-burn grazing in semi-arid landscapes of the western Great Plains in North America requires alternative grazing management strategies to create and maintain heterogeneity of habitat structure (e.g., animal unit distribution, pasture configuration), but knowledge of their effects on grassland fauna is limited. The lesser prairie-chicken (Tympanuchus pallidicinctus), an imperiled, grassland-obligate, native to the southern Great Plains, is an excellent candidate for investigating effects of heterogeneity-based grazing management strategies because it requires diverse microhabitats among life-history stages in a semi-arid landscape. We evaluated influences of heterogeneity-based grazing management strategies on vegetation structure, habitat selection, and nest and adult survival of lesser prairie-chickens in western Kansas, USA. We captured and monitored 116 female lesser prairie-chickens marked with very high frequency (VHF) or global positioning system (GPS) transmitters and collected landscape-scale vegetation and grazing data during 2013-2015. Vegetation structure heterogeneity increased at stocking densities $\leq 0.26$ animal units/ha, where use by nonbreeding female lesser prairiechickens also increased. Probability of use for nonbreeding lesser prairie-chickens peaked at values of cattle forage use values near $37 \%$ and steadily decreased with use $\geq 40 \%$. Probability of use was positively affected by increasing pasture area. A quadratic relationship existed between growing season deferment and probability of use. We found that $70 \%$ of nests were located in grazing units in which grazing pressure was $<0.8$ animal unit months/ha. Daily nest survival was negatively correlated with grazing pressure. We found no relationship between adult survival and grazing management strategies. Conservation in grasslands expressing flora community composition appropriate for lesser prairie-chickens can maintain appropriate habitat structure heterogeneity through the use of low to moderate stocking densities $(<0.26$ animal units/ha), greater pasture areas, and site-appropriate deferment periods. Alternative grazing management
\end{abstract}

Received: 21 April 2020; Accepted: 2 October 2020

${ }^{1}$ E-mail: dhaukos@ksu.edu

${ }^{2}$ Current affliation: Department of Fish and Wildlife Conservation, Virginia Tech, Blacksburg, VA 24061, USA

${ }^{3}$ Current affiliation: Department of Horticulture and Natural Resources, Kansas State University, KS 66506, USA

${ }^{4}$ Current affiliation: National Wild Turkey Federation, Emporia, KS 66801, USA

${ }^{5}$ Current affiliation: Obio Department of Natural Resources, 2045 Morse Road, Columbus, OH 43229, USA

${ }^{6}$ Current affiliation: Voyageurs National Park, 360 MN-11, International Falls, MN 56649, USA

${ }^{7}$ Current affliation: Department of Ecosystem Science and Management, University of Wyoming, 1000 E. University Avenue, Laramie, WY 82071, USA 
strategies (e.g., rest-rotation, season-long rest) may be appropriate in grasslands requiring greater heterogeneity or during intensive drought. Grazing management favoring habitat heterogeneity instead of uniform grazing distributions will likely be more conducive for preserving lesser prairie-chicken populations and grassland biodiversity. (C) 2021 The Wildlife Society.

KEY WORDS Andersen-Gill, deferment, forage use, grassland heterogeneity, lesser prairie-chicken, pasture area, resource selection function, stocking density, Tympanuchus pallidicinctus.

Grasslands are among the most imperiled ecosystems across the globe (Samson et al. 2004, Hoekstra et al. 2005), and extant grasslands are highly susceptible to anthropogenic disturbance with $>3.5$ million ha managed as pastureland for grazing (Goldewijk 2001). Grazing and periodic fire are the principal keystone drivers in maintenance and enhancement of grassland biodiversity in the Great Plains in North America. Mistargeted grazing practices, however, can negatively affect grassland species diversity, composition, function, and structure (Milchunas et al. 1988, Fleischner 1994, Knapp et al. 1999, Samson et al. 2004). Grazing intensity (i.e., forage use, grazing pressure, stocking rate), classification of grazers (i.e., sex, age, species), and spatiotemporal patterns of grazing are the primary determinants of grazing-associated effects (Fuhlendorf and Engle 2001). Grazing management designed to maximize annual livestock performance (e.g., management for vegetation homogeneity) is potentially harmful to grassland ecosystem function (Fleischner 1994; Hovick et al. 2014, 2015). Although a few wildlife species may benefit from habitat created by homogenous grazing disturbance, it is detrimental to most species, such as grassland birds, reliant on variable vegetation structure at a landscape scale (Knopf 1994). A shift in management strategy towards creating and maintaining landscape heterogeneity (i.e., variation in plant composition and structure) has been proposed to remedy these effects (Fuhlendorf et al. 2006).

The recoupling of fire and grazing (i.e., pyric herbivory) is commonly suggested and implemented as a means of creating landscape heterogeneity (Fuhlendorf et al. 2009), but a cultural pattern of fire suppression has limited the implementation of pyric-herbivory as a management tool in certain geographies (Taylor 2005). Moreover, in semi-arid systems such as the short-grass steppe of northeastern Colorado, USA, patch-burn grazing strategies alone fail to produce adequate nesting habitat for grassland bird species requiring relatively robust herbaceous microhabitat (Augustine and Derner 2015). In the absence of pyricherbivory, alternative methods for creating structural heterogeneity across spatiotemporal scales, particularly in semiarid landscapes, may be valuable. Traditional grazing systems tend to create uniform grazing disturbances by increasing stocking density (i.e., number of animal units per unit area), reducing pasture area, and increasing deferment during the growing season (i.e., proportion of growing season [Apr to $1 \mathrm{Oct}$ ] in which livestock were absent from a pasture). Thus, reversing these management actions should promote variation in spatiotemporal grazing disturbance and, subsequently, a heterogeneity-based vegetation response to grazing (Fuhlendorf and Engle 2001). A growing body of evidence describes how domestic grazers perceive, interact with, and affect their environment on the Great Plains (Launchbach and Howery 2005, Derner et al. 2009, Allred et al. 2011). Additional insights from experimental design focused on the effects of grazing disturbances on vegetation structure metrics empirically related to a wildlife species resource selection and fitness would also be valuable (Fritts et al. 2018; Smith et al. 2018; Milligan et al. 2020a, b).

In the Great Plains, prairie grouse are grassland-obligate species that require vegetation heterogeneity across broad landscapes to complete their life cycle (Haukos and Zavaleta 2016, Milligan et al. 2020a). Livestock grazing on extant grasslands has the potential to affect habitat quality for prairie grouse through changes in vegetation composition and structure. Previous investigations have assessed prairie grouse response to grazing strategies intended to promote landscape heterogeneity (e.g., patch-burn grazing, rest-rotation grazing) in vegetation relative to traditional grazing strategies (e.g., continuous grazing, annual burning and high intensity grazing) that create vegetation homogeneity across pastures. Milligan et al. (2020a, b,c) reported that rest-rotational grazing did not influence nest success or female survival of sharp-tailed grouse (Tympanuchus phasianellus) but found a weak positive relationship with placement of home range during the breeding season. Female greater prairie-chickens (T. cupido) monitored on lands managed with patch-burn grazing had annual survival estimates $35 \%$ greater than those managed with annual burning and intensive early cattle stocking (Winder et al. 2018). Female greater prairie-chickens monitored at properties managed with patch-burn grazing selected areas with low stocking rates and high fire frequencies but avoided recently burned areas (Winder et al. 2016). Smith et al. (2018) reported equivocal effects of livestock presence and indices of local livestock use on nest-site selection and survival of greater sage-grouse (Centrocercus urophasianus). No published studies relate space use, resource selection, and demographics of prairie grouse populations to specific grazing metrics such as intensity, deferment, forage use, and pasture size.

The lesser prairie-chicken ( $T$. pallidicinctus) occupies semiarid grasslands and shrublands of the southwestern Great Plains and requires heterogeneous environments to fulfill all life-stage needs (Fig. 1; Haukos and Zavaleta 2016). In particular, as primary factors influencing population demography, female lesser prairie-chickens transition among 


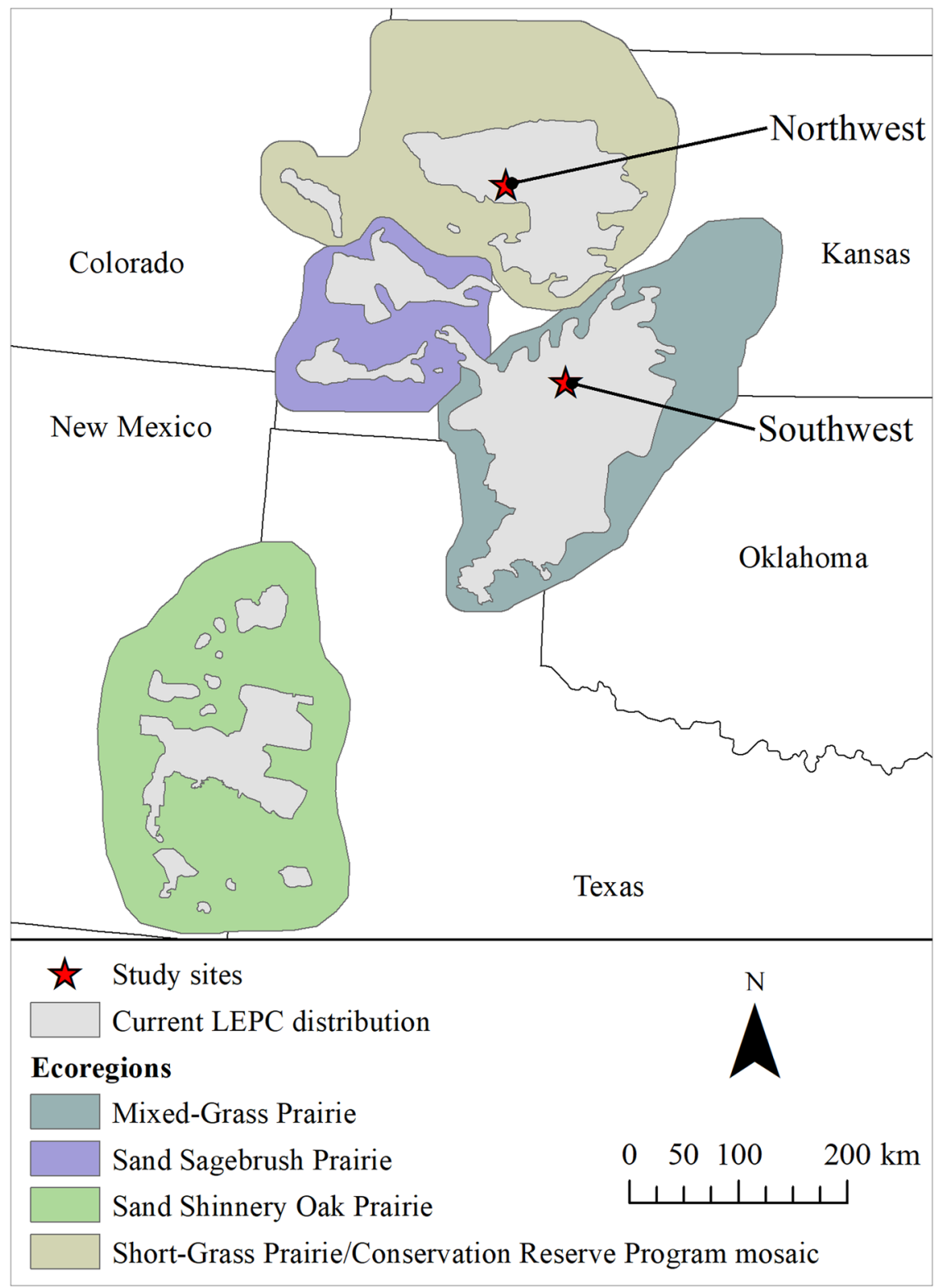

Figure 1. Study area locations where we assessed lesser prairie-chicken (LEPC) population response to livestock grazing from 2013-2015 in relation to lesser prairie-chicken distribution and ecoregions in the Southern Great Plains, USA (McDonald et al. 2014). The Northwest study area was located within Logan and Gove counties, Kansas, USA, and the Southwest study area was located within Clark County, Kansas.

a wide range of vegetation composition and structure types across all reproductive states (Hagen et al. 2009, 2013; Lautenbach 2015; Haukos and Zavaleta 2016; Lautenbach et al. 2019). When grazing management objectives are conceptualized with a goal of creating lesser prairie-chicken microhabitat, recommendations often include creation of habitat heterogeneity to accommodate nesting and brooding habitat needs by referencing a range of structural vegetation metrics (e.g., visual obstruction, height, and canopy cover; Fritts et al. 2016, Haukos and Zavaleta 2016, Lautenbach et al. 2019). Typically, a negative relationship between lesser prairie-chicken habitat quality and grazing disturbance is assumed, with recommendations generally including a light to moderate stocking rate or forage use (e.g., 33-50\%; Hagen et al. 2004, Kansas Natural Resources Conservation Service
2014). Short-duration grazing at moderate grazing intensity ( $50 \%$ forage use) was benign or beneficial to lesser prairiechicken nesting ecology and adult survival, respectively, in sand shinnery oak (Quercus havardii) ecosystems of southeastern New Mexico, USA (Fritts et al. 2016, 2018). The effectiveness of managed grazing to create landscape heterogeneity, conditional on regional variation in precipitation, soils, and vegetation productivity, for conservation of lesser prairie-chickens on private lands is poorly understood (Giesen 1994, Hagen and Elmore 2016, Hagen et al. 2017).

Grazing management prescriptions developed to enhance lesser prairie-chicken habitat may influence management of livestock operations. Landowner incentive programs such as the Lesser Prairie-Chicken Initiative through the United States Department of Agriculture Natural Resources 
Conservation Service and Western Association of Fish and Wildlife Agencies Range-wide Conservation Plan targeted potential monetary gaps between livestock production and grazing management to improve lesser prairie-chicken habitat (Van Pelt et al. 2013). Assessing the ability for heterogeneity-based grazing management to balance lesser prairie-chicken habitat and livestock production goals would be useful to optimize cost-effectiveness of future conservation efforts on private working lands.

Our objectives were to evaluate how heterogeneity-based grazing influenced vegetation structure in semi-arid environments, and could be used to manage habitat for female lesser prairie-chickens. We predicted that larger pastures, exhibiting reduced stocking densities and deferment periods, would contain the greatest habitat heterogeneity at the pasture scale. We hypothesized that lesser prairiechickens would respond differentially to variation in grazing disturbance. We predicted a nonlinear relationship between probability of use and increasing grazing pressure. We predicted a positive relationship between female lesser prairie-chicken resource use (nonbreeding space use and nest-site selection) and larger pastures, decreased stocking density, and shorter deferment period. Third, we predicted that nest survival and adult female survival would mirror relationships between habitat use and grazing management.

\section{STUDY AREA}

Our research was concentrated on portions of 3 large ranches located in 2 distinct areas of the Short-Grass Prairie/Conservation Reserve Program (CRP) Mosaic Ecoregion (i.e., Northwest) and confluence of the Sand Sagebrush Prairie and Mid-Grass Prairie (i.e., Southwest) ecoregions where densities of lesser prairie-chickens were relatively high in western Kansas, USA, during 2013-2015 (Fig. 1; McDonald et al. 2014). The Northwest study area was focused on 2 study sites dominated by private land within Logan and Gove counties in northwest Kansas ( $785 \mathrm{~m}$ elevation). Topography included numerous draws, ravines, and wooded riparian areas intersecting a relatively level landscape. The Southwest study area was located on private lands south of Ashland, Kansas, within Clark County ( $615 \mathrm{~m}$ elevation). Topography was primarily flat with little change in elevation, and included the Cimarron river on the southern edge of the study area. The ranches comprised 25,259 ha, of which we included 13,398 ha in 33 pastures in this study. Primary land uses for both study areas were livestock grazing, energy exploration and extraction, and both dryland and irrigated row-crop agriculture. Conservation Reserve Program grasslands and row-crop agriculture were more abundant in Northwest than Southwest (Robinson et al. 2018). In the Northwest study area, mean annual precipitation was $48.7 \mathrm{~cm}$ with an overall average annual temperature of $11.1^{\circ} \mathrm{C}$. Average annual maximum temperature was $20.0^{\circ} \mathrm{C}$ and average annual minimum temperature was $2.1^{\circ} \mathrm{C}$ (United States Climate Data, http://usclimatedata. com, accessed 15 Jan 2018). Annual precipitation during the 2013-2015 study period was similar to the long-term average: $45.0,55.1$, and $49.4 \mathrm{~cm}$, respectively. The Southwest study area had a mean annual precipitation of $61.8 \mathrm{~cm}$ with an overall average annual temperature of $13.3^{\circ} \mathrm{C}$. Average annual maximum temperature was $21.3^{\circ} \mathrm{C}$ and average annual minimum temperature was $5.2^{\circ} \mathrm{C}$ (United States Climate Data, http://usclimatedata. com, accessed 15 Jan 2018). Annual precipitation during the 2013-2015 study period was slightly less than the long-term average in $2013(41.0 \mathrm{~cm})$, similar to the longterm average in $2014(59.7 \mathrm{~cm})$, and slightly greater than the long-term average in $2015(78.7 \mathrm{~cm})$. Primary occurrence of precipitation was from April to August as thunderstorms, with occasional precipitation as frontal events during fall (Sep-Dec). Winter was usually dry and windy with occasional snow events.

Predominant soil and community types (ecological sites) in the Northwest study area included limy upland, loamy upland, chalk flats, and loamy lowland. The Southwest study area was dominated by saline subirrigated, subirrigated, sandy, and sands sites. Dominant grasses in the Northwest study area included blue grama (Bouteloua gracilis), buffalograss (B. dactyloides), and western wheatgrass (Pascopyrum smithii). In addition to blue grama, dominant grasses in the Southwest study area were alkali sacaton (Sporobolous airoides) and sand dropseed (S. cryptandrus). Dominant fauna in the Northwest study site consisted of coyote (Canis latrans), swift fox (Vulpes velox), striped skunk (Mephitis mephitis), northern harrier (Circus cyaneus), Swainson's hawk (Buteo swainsoni), red-tailed hawk (Buteo jamaicensis), ring-necked pheasant (Phasianus colchicus), white-tailed deer (Odocoileus virginianus), and mule deer (O. hemionus). Dominant fauna in the Southwest study site consisted of coyote, striped skunk, American badger (Taxidea taxus), northern harrier, red-tailed hawk, ring-necked pheasant, and white-tailed deer.

\section{METHODS}

\section{Capture and Bird Locations}

We used walk-in funnel traps and drop nets to capture female lesser prairie-chickens on leks during spring (midMar through mid-May) of 2013-2015 (Haukos et al. 1990, Silvy et al. 1990). We fitted captured females with either a very high frequency (VHF) radio-transmitter or global positioning system (GPS) satellite-transmitter (platform transmitting terminals [PTT]). We attached VHF transmitters $(12 \mathrm{~g}$ or $15 \mathrm{~g})$ with an estimated battery life of 790 days using a bib-style harness to individuals $>500 \mathrm{~g}$ (Advanced Telemetry Systems, Isanti, MN, USA). We fitted solar-powered GPS-PTT (22 g, PTT-100, Microwave Telemetry, Columbia, MD, USA) transmitters to females weighing $>700 \mathrm{~g}$ using a rump-style harness method (Dzialak et al. 2011). We released marked lesser prairiechickens at the lek of capture. All capture and handling procedures were approved by the Kansas State University Institutional Animal Care and Use Committee (protocol 3241) and Kansas Department of Wildlife, Parks and 
Tourism scientific wildlife permits (SC-042-2013, SC-0792014, SC-001-2015).

We monitored radio-tagged birds from March 2013 through February 2016. We located VHF-fitted females using fixed-location triangulation 3-4 times/week throughout the lifespan of the bird or transmitter (Cochran and Lord 1963). We used handheld receivers and 3-element Yagi antennae to collect $\geq 3$ bearings/location. We entered telemetry bearings into Location of a Signal software (Ecological Software Solutions, Hegymagas, Hungary) to obtain Universal Transverse Mercator coordinates of the estimated location. We generally limited error polygons of each estimated bird location to $0.1 \mathrm{ha}$. We monitored status of each VHF-tagged female via an 8-hour mortality switch installed in the transmitter. We obtained fixes of GPS-PTT locations every 2 hours during 0600-2400 (depending on sunlight and battery charge). Recorded GPS fixes uploaded to ARGOS satellites every 3 days. Potential error of these points was $<18 \mathrm{~m}$. If we obtained a mortality signal, we used either homing (VHF) or previous GPS locations to locate the transmitter and identify cause-specific mortality or another reason for transmitter loss.

\section{Grazing Management Information}

Fifty-five pastures across the 3 ranches represented a gradient of grazing intensities and management strategies available to relatively high densities of lesser prairiechickens. For functionality and efficiency, ranch managers within our study sites generally rotated cattle through pastures while keeping animal units (i.e., herd size) and forage consumption goals constant (e.g., 50\% forage use for all pastures). Producers provided grazing management records of animal class (e.g., female and calf, male) herd size, average mass, and grazing duration in each pasture. We delineated pasture boundaries and calculated area (ha) for each pasture using the calculate geometry tool in ArcGIS 10.2 (Esri, Redlands, CA, USA).

We categorized 3 metrics in grazing management as indicators of potential increased within-pasture microhabitat heterogeneity: increased pasture size, decreased stocking density, and shorter period of livestock deferment during the growing season. Collectively, we defined implementation of these patterns as heterogeneity-based grazing management. We used recorded grazing data and pasture area calculations to determine grazing pressure (animal unit months/ha [AUM/ha]), stocking density (animal unit/ha [AU/ha]), and deferment (proportion of growing season in which cattle were absent [Apr-Sep]). We calculated grazing pressure at weekly intervals during each grazing period for each year.

In conjunction with pasture boundaries, we created ecological site maps using ArcGIS 10.2 (U.S. Department of Agriculture [USDA] 2013). We estimated the area (ha) within each pasture occupied by unique ecological sites (USDA 2013). We obtained expected average annual forage production estimates from state and transition models unique to each defined ecological site (USDA 2013). We estimated the expected forage available in each pasture by multiplying the area (ha) of each unique ecological site by the average predicted annual forage production $(\mathrm{kg} / \mathrm{ha})$. We summed each unique ecological site present within a given pasture to obtain an estimate for available forage expected during average precipitation conditions. This would be the likely approach to estimate available forage by producers with large ranches and multiple grazing units. Using grazing pressure calculations, we determined forage consumption estimates for each pasture based on an expected forage efficiency of $50 \%$ and a consumption rate of $363 \mathrm{~kg} / \mathrm{month} / 1.0 \mathrm{AU}$ (454-kg female; Holechek et al. 1989). To estimate forage use for each pasture, we multiplied the forage consumption estimate by 2 (to account for the destruction of forage via trampling, urinating, and defecating) and divided by the expected available forage. We estimated forage use values at weekly intervals during grazing periods to provide a cumulative measure of disturbance as grazing events progressed. Summary of the spatial and temporal scale for grazing variables are available online in Supporting Information (Table S1).

\section{Vegetation Heterogeneity}

To determine effects of vegetation heterogeneity on selection by lesser prairie-chickens, we conducted standardized vegetation surveys at each ranching operation using 33 existing pastures as experimental units with an average area of 406 ha (Table S2, available online in Supporting Information). We completed surveys during October to March 2014-2015. We either randomly generated vegetation survey points within monitored pasture units (i.e., available) using the create random points tool in ArcGIS 10.2 or randomly selected points from a pool of locations obtained from marked female lesser prairie-chickens. All survey points were limited to grassland pastures in which we collected grazing management data.

At each survey point, we recorded a $100 \%$ visual obstruction reading (VOR; the maximum height in cm completely visually obscured by vegetation) in each cardinal direction using a Robel pole at plot center from a distance of $4 \mathrm{~m}$ and height of $1 \mathrm{~m}$ (Robel et al. 1970). We recorded the tallest vegetation present within a $60 \times 60-\mathrm{cm}$ quadrat located at plot center, and $4 \mathrm{~m}$ out from plot center in each cardinal direction (Daubenmire 1959).

We then binned averaged readings for each survey point with others of identical sampling period and pasture. Secondarily, we calculated the mean, coefficient of variation, and standard deviation of $100 \%$ VOR $(\mathrm{cm})$ and vegetation height $(\mathrm{cm})$ across each bin of survey points (binned by pasture). We also calculated grazing management components (grazing pressure, forage use, stocking density, pasture area, deferment) for each pasture and paired components with the appropriate vegetation calculations. We did not perform vegetation surveys in a given pasture until grazing was completed for the year. For each grazing management component, we divided survey points into 2 groups: above the median and below the median. We used 2 -sample $t$-tests to compare vegetation values above and below the median for each grazing management component. We set $\alpha=0.05$. 


\section{Nonbreeding Habitat and Nest-Site Selection}

We evaluated habitat selection during 2013-2016 using mixed-effect resource selection functions (RSF; Boyce et al. 2002, Manly et al. 2002, Gillies et al. 2006). We employed RSFs to evaluate nonbreeding habitat (Oct-Mar) and nest-site selection by female lesser prairie-chickens. Each RSF incorporated a used versus available study design limited to contiguous portions of each ranch with available grazing data (Boyce et al. 2002, Manly et al. 2002).

For each nonbreeding RSF, we distributed 1 random location for each time- and date-stamped lesser prairiechicken location using the create random points tool in ArcGIS 10.2. We constrained random locations to pastures within each study site to facilitate comparison among used and available pastures. Within study sites, pastures were well within the average dispersal distance of lesser prairiechickens $(\sim 16 \mathrm{~km})$ and therefore available (Earl et al. 2016). The development of RSF model sets was a 2 -fold process. First, we developed a nonbreeding RSF model set to establish baseline habitat selection response of nonbreeding females to the intensity of grazing observed within our study sites. Second, we evaluated effects of heterogeneity-based grazing management strategies in the context of increasing grazing intensity. The grazing intensity model set included linear and nonlinear (quadratic) predictors of grazing pressure (AUM/ha) and forage use (\%). We included the grazing intensity variable found to be the most influential in nonbreeding habitat selection in all secondary model sets as important context to interpreting the multifaceted response of female lesser prairie-chickens to grazing. Additionally, we suspected the inclusion of an objective grazing intensity metric in secondary model sets would be essential for applicable interpretation of results. We developed 3 secondary model sets ( 1 for each heterogeneity-based management strategy) to investigate our questions and hypotheses regarding linear and nonlinear predictors of deferment, stocking density, and pasture area. These will be referred to individually as the deferment, stocking density, and pasture area models.

Our nest dataset for testing included nest locations from successful ( $\geq 1$ egg hatched/nest) and unsuccessful (failed nest or no recorded nest attempt) breeders. Because of our limited sample of nests due to the lag effect of grazing factors affecting nest-site selection (e.g., 2015 nest-site selection in response to grazing practices in 2014), we developed 1 set of models to evaluate nest-site selection. Nests require residual vegetation cover and at the time of nest-site selection, current year grazing disturbance generally has little influence on available nest sites (Hagen et al. 2004). Thus, we assigned grazing management components from the previous year to used and available nest sites. For example, a covariate associated with a nest in May of 2015 describes grazing during the 2014 grazing year (Apr 2014-Mar 2015). The nest-site RSF model set included 17 a priori models that evaluated our predictions for grazing disturbance and heterogeneity-based grazing management strategies.

In nonbreeding and nest-site-selection RSFs, we did not include explanatory variables exhibiting a correlation of $|r|>0.7$ in the same model. We included bird and nest identification as a random effect (random intercept) in nonbreeding RSFs and nest-site selection models, respectively (Gillies et al. 2006). Additionally, we included a random intercept of ranch in all RSF model sets. We $z$-transformed all continuous variables to address scaling issues among predictors and back-transformed variables for plotting response curves. We included a null (constant) model in each model set. We excluded year and site variables from our model set because the range of grazing intensities represented would have been reduced. We conducted all RSF analyses in Program R (version 3.0.1, R Foundation for Statistical Computing, Vienna, Austria) using the glmer() function within the lme4 package (Bates et al. 2015).

\section{Nest Location and Survival}

We identified nest locations by homing in on VHF-marked females after females were in the same relative location for 3 consecutive days (Pitman et al. 2005, Lautenbach et al. 2019). We monitored females marked with GPS-PTTs remotely until GPS locations indicated nest initiation or early incubation. We approached nests wearing rubber boots and latex gloves to reduce possible scent trails. At first nest visit, we flushed the female and floated her eggs to estimate date of incubation ( $\mathrm{McNew}$ et al. 2009). We monitored each nesting female daily during 2013-2015 until locations indicated that the female had left the nest. We considered nests successful if we found $\geq 1$ egg exhibiting pipping, intact egg membranes, or chicks with females following hatching; otherwise, we classified the nest as unsuccessful.

We used the nest survival model in Program MARK to determine if grazing disturbance influenced nest survival of lesser prairie-chickens (White and Burnham 1999). We tested linear effects of grazing pressure, forage use, stocking intensity, deferment, pasture area, and date of the nesting season on nest survival. We examined correlations of covariates and did not include correlated $(|r|>0.7)$ covariates in the same model. We developed 24 models in an a priori model set that tested hypotheses related to grazing management components and daily survival rate, and estimated overall nest survival for an average exposure period of 38 days (Lautenbach et al. 2019).

\section{Adult Survival}

We used an Anderson-Gill model to evaluate how continuous, encounter-specific grazing management covariates affect hazard rates for female lesser prairie-chickens throughout the study period (Dinkins et al. 2014). We used Cox proportional hazard models to evaluate the influence of our grazing management strategies (Andersen and Gill 1982). We used all available locations for encounters of VHF-marked lesser prairie-chickens. We randomly selected PTT-marked bird locations at the rate of 1 point per bird per day from 8-10 points available per day. The frequency of locations allowed for modeling of daily survival using a daily encounter history. We randomly selected available locations for each day using the r.sample command in Geospatial Modeling Environment 
(Beyer 2012). We used only points and mortalities located within monitored cattle operations. We created an a priori model set using predictors of grazing intensity and heterogeneity-based grazing management tools. We limited models to single variables because we recorded few mortalities. We tested model diagnostics with the cox.zph function to determine if these data met assumptions for proportional hazard functions (Fox and Weisberg 2011). Additionally, we used Kaplan-Meier methodology to estimate annual survival (Kaplan and Meier 1958).

For all analyses, we used an information-theoretic approach, Akaike's Information Criterion adjusted for small sample sizes $\left(\mathrm{AIC}_{c}\right)$, to rank and select individual models for inference within each model suite (Anderson and Burnham 2002). We considered models with $\Delta \mathrm{AIC}_{c} \leq 2$ to be equally parsimonious. If beta estimates from top models differed from zero (i.e., 95\% CIs did not overlap zero), then we determined the variable to be influential and plotted the relative probability of use curve (effects package; Ihaka and Gentleman 1996).

\section{RESULTS}

We captured 116 female lesser prairie-chickens during spring 2013-2015. Our pooled nonbreeding VHF and GPSPTT location dataset included 7,018 nonbreeding lesser prairie-chicken locations and an equal number of random points. Grazing pressure ranged from 0-2.31 AUM/ha $(\bar{x}=0.47 \pm 0.37[\mathrm{SD}] \mathrm{AUM} / \mathrm{ha})$. Estimated forage use values ranged from $0-77 \%(\bar{x}=15.0 \pm 12.2 \%)$. Stocking density ranged from $0-0.96 \mathrm{AU} / \mathrm{ha}(\bar{x}=0.31 \pm 0.25 \mathrm{AU} / \mathrm{ha})$. Pasture area ranged from $33-736$ ha $(\bar{x}=464.29 \pm$ $166.69 \mathrm{ha})$. Growing season deferment across all locations ranged from $0-100 \%$ of the growing season $(\bar{x}=73.32 \pm$ 18.41\%). Density distributions varied between used and available locations for forage use, pasture area, deferment, and stocking density (Fig. 2).

\section{Vegetation Heterogeneity}

We sampled 914 random points in 33 pastures $(\bar{x}=$ 27.7 points/pasture) to assess effect of grazing management on vegetation heterogeneity. We calculated means, coefficients of variation, and corresponding standard deviations of visual obstruction $(100 \% \mathrm{~cm})$ and vegetation height $(\mathrm{cm})$ for 2 grazing intensity predictors (grazing pressure and forage use) and 3 heterogeneity-based grazing management tools (stocking density, pasture area, deferment) across 33 pastures; we used 26 pastures for stocking density models during 2 sampling years (Table S2, available online in Supporting Information). As stocking density decreased, vegetation density was more variable (i.e., heterogeneous). Pastures subjected to relatively lower values of stocking density $(<0.26 \mathrm{AU} / \mathrm{ha})$ had more heterogeneous vegetation density, exhibiting roughly $40 \%$ greater values of standard deviation $\left(t_{21.067}=2.79, P=0.01\right)$ and coefficient of variation $\left(t_{18.89}=3.17, P=0.005\right)$ for $100 \%$ VOR than pastures subjected to relatively greater values of stocking density (>0.26 AU/ha; Fig. 3; Table S3, available online in Supporting Information). We did not detect any other significant relationships during vegetation response analyses.
A
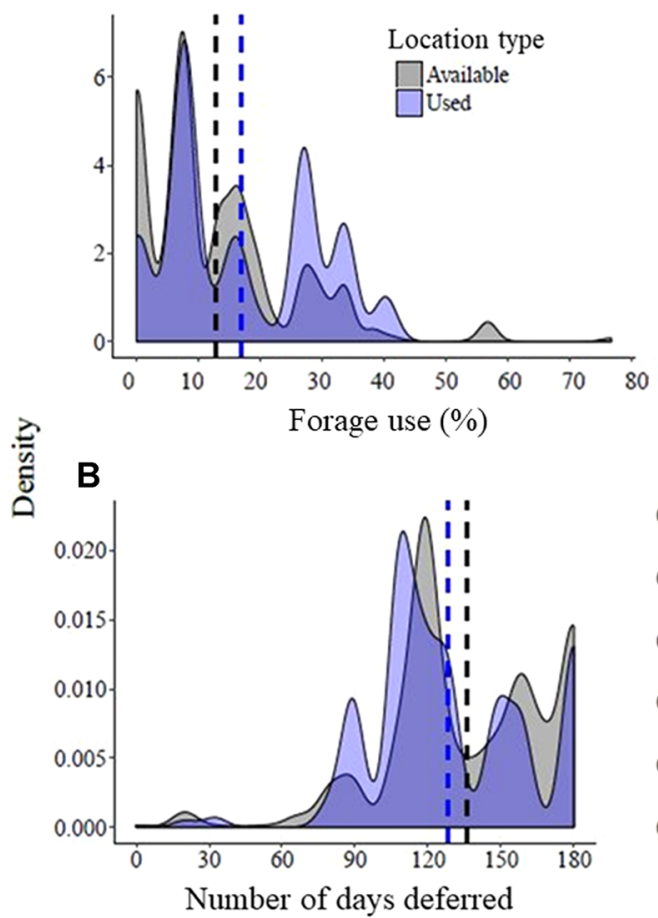

C

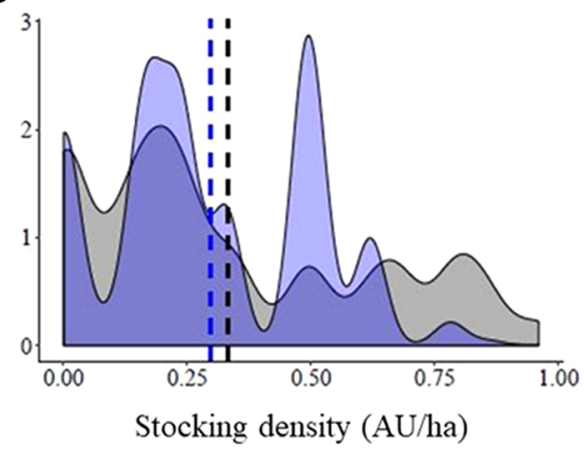

D

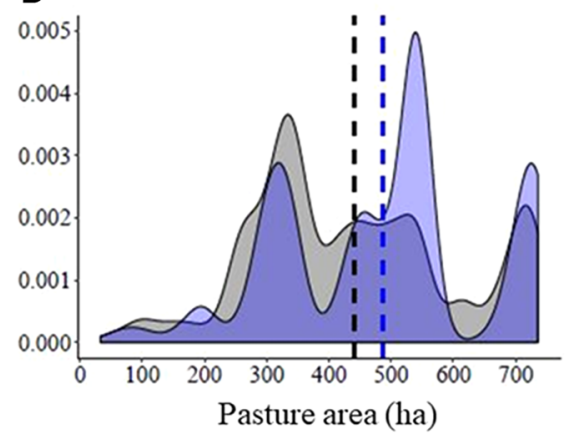

Figure 2. Density distributions of available and used locations obtained for resource selection functions evaluating the influence of grazing management components A) forage use, B) number of growing season days deferred, C) stocking density (animal units [AU]/ha), and D) pasture area on nonbreeding habitat selection by female lesser prairie-chickens in monitored grasslands, western Kansas, USA, 2013-2016. Vertical dashed lines represent the means associated with each set of available (black) and used (blue) locations. 

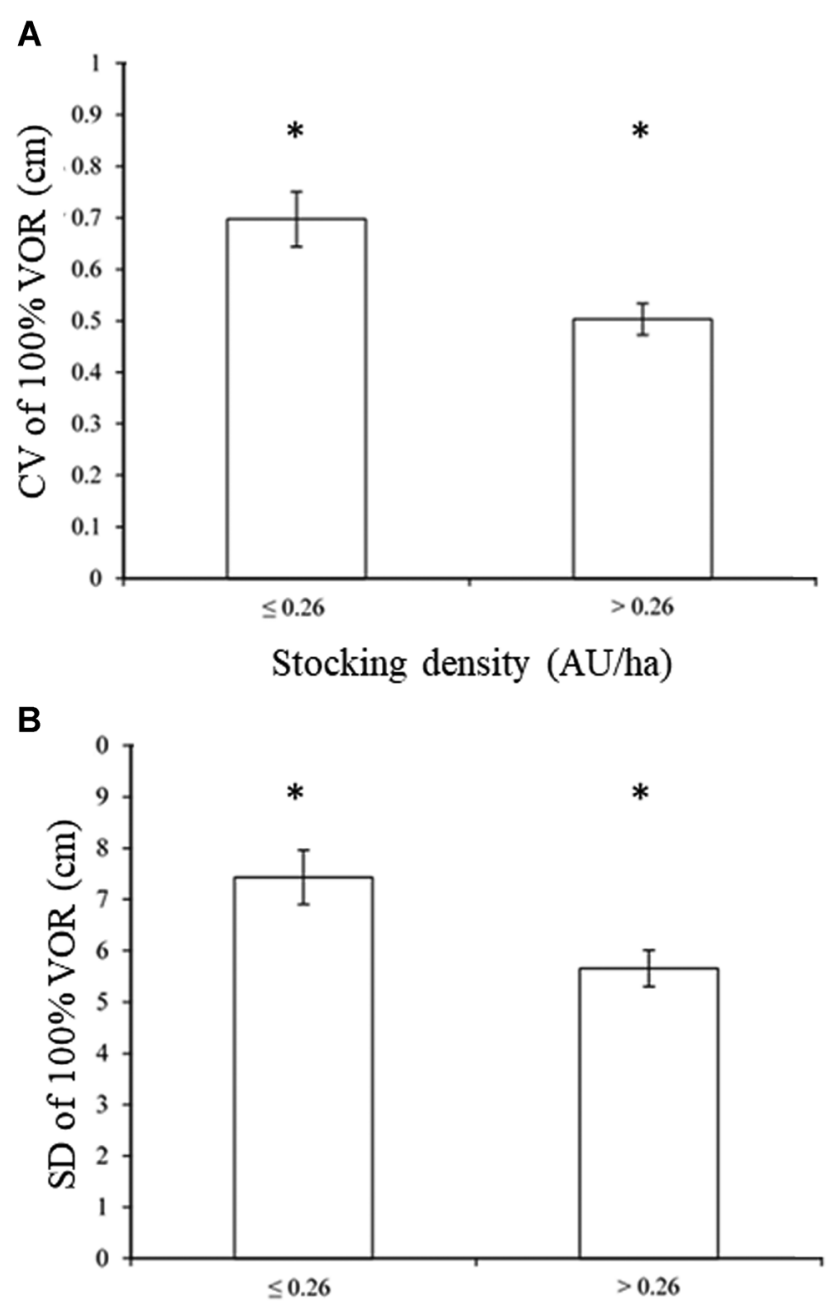

Stocking density (AU/ha)

Figure 3. Mean estimates and standard errors of $A$ ) coefficient of variation $(\mathrm{CV})$ of $100 \%$ visual obstruction (VOR; $\mathrm{cm}$ ) and $\mathrm{B}$ ) standard deviation (SD) of $100 \%$ VOR $(\mathrm{cm})$ associated with 2 categories of stocking density $(\leq 0.26$ and $>0.26$ animal units/ha $[\mathrm{AU} / \mathrm{ha}])$ applied to pastures in western Kansas, USA, 2013-2015. An asterisk $\left(^{*}\right)$ denotes that means differed as determined by a 2 -sample $t$-test $(P<0.05)$.

\section{Nonbreeding Habitat and Nest-Site Selection}

For nonbreeding habitat selection, the results of the grazing intensity model set identified a quadratic relationship with forage use with $100 \%$ of model weight (Table 1). The variance associated with the random effects of bird and ranch were $0.025(\mathrm{SD}=0.159)$ and $0.088(\mathrm{SD}=0.029)$, respectively. Relative probability of use exhibited a quadratic relationship with forage use and lesser prairie-chicken habitat selection, with selection being the greatest close to $40 \%$ (Fig. 4). The quadratic effect of forage use was included in all secondary nonbreeding RSF model sets because it was the best predictor of the baseline response of lesser prairie-chickens to increasing grazing disturbance.

The top-ranked RSF model in the pasture area model set included additive influences of forage use, forage use ${ }^{2}$, and pasture area (Table 1). The variance associated with the random effects of bird and ranch were $0.026(\mathrm{SD}=0.160)$ and $0.059(\mathrm{SD}=0.243)$, respectively. The positive beta associated with pasture area and our model output indicated a positive linear relationship between pasture size and habitat selection by female lesser prairie-chickens (Table 2; Fig. 4).

The top-ranked model in our deferment model set was an interaction between forage use ${ }^{2}$ and deferment ${ }^{2}$ (Table 1). The variance associated with the random effects of bird and ranch were $0.048(\mathrm{SD}=0.229)$ and $0.139(\mathrm{SD}=0.374)$, respectively. Probability of use was lowest when pastures were deferred for approximately $40 \%$ of the growing season (Fig. 4). The second-ranked model of the additive version forage use $^{2}$ and deferment ${ }^{2}$ was equally parsimonious $\left(\Delta \mathrm{AIC}_{c}=0.92\right.$; Table 1$)$.

The top-ranked model in the stocking density model set included additive effects of forage use, forage use ${ }^{2}$, and stocking density and an interaction between stocking density and forage use ${ }^{2}$ (Table 1 ). The variance associated with the random effects of bird and ranch were 0.052 $(\mathrm{SD}=0.229)$ and $0.444(\mathrm{SD}=0.666)$, respectively. Beta estimates indicated a negative relationship between stocking density and probability of lesser prairie-chicken use (Table 2). At mean values of forage use, the stocking density response curve indicated a $75 \%$ drop in relative probability of use when stocking densities were near zero AU/ha and a relative probability of use of approximately $15 \%$ as stocking density approached 1.0 AU/ha. The relationship between stocking density and forage use yields an increase in probability of use as stocking density decreases at forage use values from $0-80 \%$ (Fig. 4).

Five models of nest-site selection were equally parsimonious with values $\leq 2 \Delta \mathrm{AIC}_{c}$, all of which included the quadrat relationship of grazing pressure (Table 3). The top model reported variances of $0.000(\mathrm{SD}=0.000)$ and 1.703 $(\mathrm{SD}=1.305)$ for unique nest and ranch, respectively. Our results indicated that only the quadratic relationship of grazing pressure was an influential predictor of nest-site placement being a variable in 7 of the 8 top-ranked models (Tables 2,3). The quadratic relationship of grazing pressure illustrated that the relative probability of nest-site placement was maximized near 1.2 AUM/ha (Fig. 5).

\section{Nest-Site Location and Survival}

We located and monitored 37 nests within grazed pastures in our study sites. All nests were located in pastures exhibiting forage use values below 40\%. Twenty-six of $37(70 \%)$ nests were located where grazing pressure was $<0.8 \mathrm{AUM} / \mathrm{ha}$.

We modeled daily nest survival for 34 nests; we censored 3 nests because they failed before we located them. Of the 34 nests, 28 were first attempts and 6 were renests. Drawing inference from our constant model, the daily survival rate of monitored nests was $0.983(95 \% \mathrm{CI}=0.972-0.989)$. Nest success for the 38-day exposure incubation period was $50.1 \%$. Seven of our 24 a priori nest survival models had a $\Delta \mathrm{AIC}_{c} \leq 2$, but all of these models included a quadratic trend of day over the nesting season (date + date $^{2}$; Table 4). The top-ranked model excluded all grazing metrics but supported a quadratic trend of day over the nesting season $\left(\right.$ date + date $\left.^{2}\right)$, indicating that all other variables in the 
Table 1. Model ranking for resource selection functions, based on Akaike's Information Criterion corrected for small sample size (AIC $)$, evaluating habitat selection by female lesser prairie-chickens within monitored working grasslands in Kansas, USA, 2013-2015. We developed model sets to investigate grazing intensity (1), and heterogeneity-based grazing management $(2,3,4)$ influences on nonbreeding habitat selection. Model sets include the following variables: forage use ( $\%$ of forage consumed or destroyed), grazing pressure (index of grazing units per area over time; animal unit month [AUM]/ha), pasture area (size of pasture unit; ha), deferment (number of days during the grazing season [Apr-Sep] a pasture unit is void of cattle), and stocking density (number of grazing units per unit area; animal unit $[\mathrm{AU}] / \mathrm{ha})$. We include number of parameters $(K)$, deviance $(\mathrm{Dev})$, and Akaike weight $\left(w_{i}\right)$ for each model.

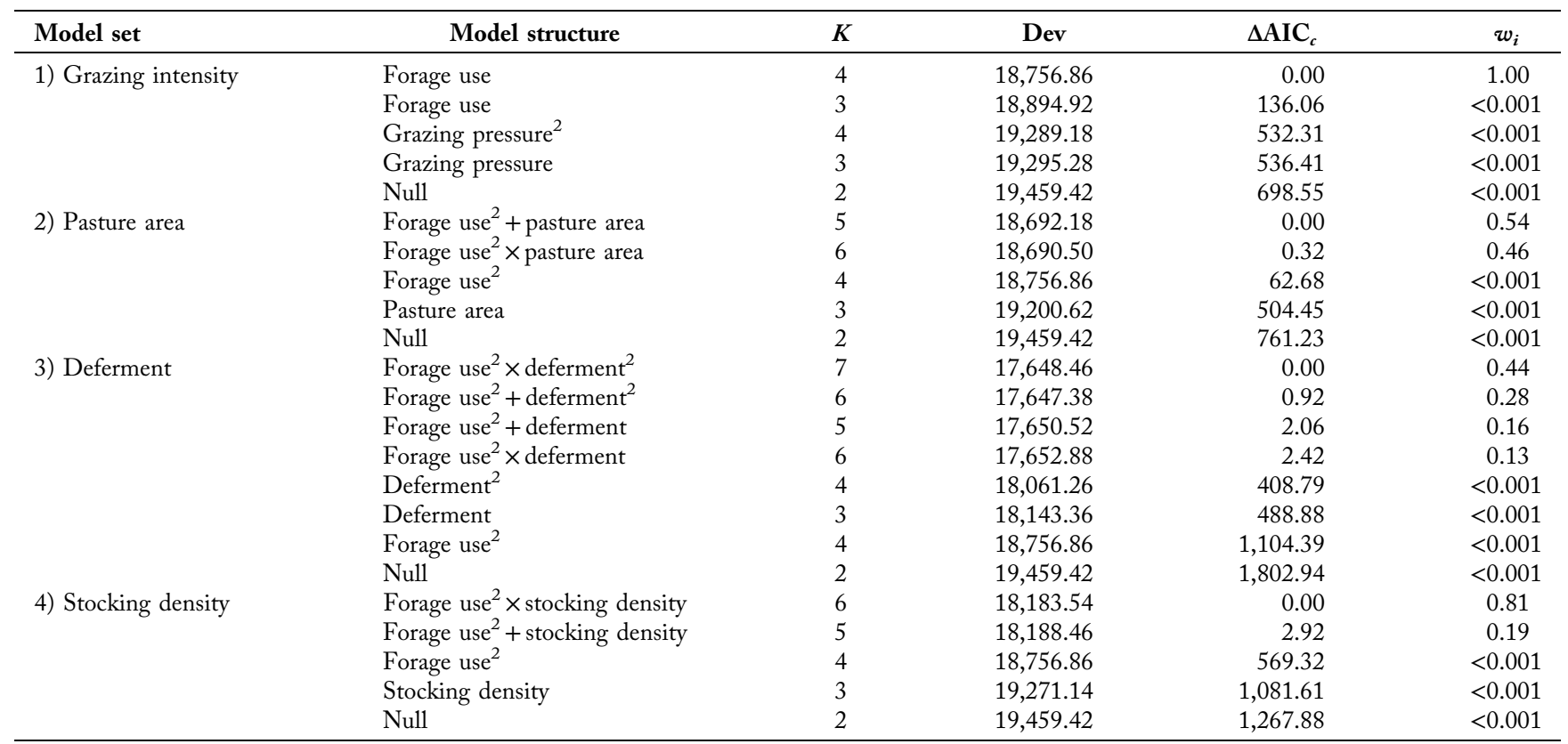

potentially competitive models were spurious. Grazing pressure occurred in the second- and third-best supported models (Table 4). Stocking density also occurred in the second-ranked model but was an uninformative parameter. Daily nest survival estimates were lowest $(0.968-0.970)$ between days 25 and 32 of the exposure period for each nest. The top-ranked model with grazing effects predicted a negative relationship between grazing pressure and daily survival, but it was not measurably different from zero $\left(\beta_{\text {grazing pressure }}=-1.53,95 \% \mathrm{CI}=-3.36-0.29 ;\right.$ Fig. 6). Although a positive relationship was indicated by the stocking density beta estimate ( $\beta_{\text {stocking density }}=2.49,95 \%$ $\mathrm{CI}=-1.06-6.04)$, it was not measurably different from zero.

\section{Adult Survival}

We used 14 mortality events and 39 bird years to model the effect of grazing management components on hazard rates. Our model selection indicated the null model was the best predictor of survival within our model set, but there was considerable model uncertainty $\left(\Delta \mathrm{AIC}_{c} \leq 2\right.$; Table 5$)$. The overall annual survival rate of female lesser prairie-chickens across all study sites was $0.317 \quad(\mathrm{SE}=0.107, \quad 95 \%$ $\mathrm{CI}=0.16-0.62)$.

\section{DISCUSSION}

Overall, our results suggest that lesser prairie-chickens respond positively to light to moderate grazing disturbances (e.g., forage use $<50 \%$ and stocking densities $<0.26 \mathrm{AU} / \mathrm{ha}$ ) in semi-arid environments based on expected production for the ecological sites defined by soil types and precipitation. Heterogeneity-based grazing strategies also promoted habitat quality for an increased number of grassland species compared to grazing strategies prioritizing standardized, uniform grazing distributions (Pavlacky et al. 2019). Our research concentrated on ranching operations that had a relatively long history of implementing light to moderate grazing intensities that supported high densities of lesser prairiechickens. Ranches within our study areas that implemented heavy grazing ( $>60 \%$ forage use) intensities did not support lesser prairie-chickens in sufficient numbers to be included in the study, but each of our study ranches contained pastures that sustained heavy grazing intensities and emulated what was occurring on adjacent properties but at larger scales. Our results support the conclusion of Fritts et al. (2016) that increasing levels of grazing disturbance, past critical thresholds (i.e., 40\% forage use, grazing pressure $>1.2 \mathrm{AUM} / \mathrm{ha}$ ), negatively affected female habitat selection and potentially nest success. We concur with Milligan et al. (2020a) that a wider range of forage use rates may have revealed stronger effects on selection and possibly demographic rates, but our findings were consistent with the conclusion that greater than moderate grazing intensity negatively influence use by lesser prairie-chickens.

In continuous grazing systems, the creation of heterogeneity is contingent on the awareness of forage quality, subsequent competition among grazers for quality forage, and realized distribution of grazing pressure across a pasture (Hart et al. 1988, Fuhlendorf and Engle 2001, Fuhlendorf et al. 2006). The forage quality-grazing 

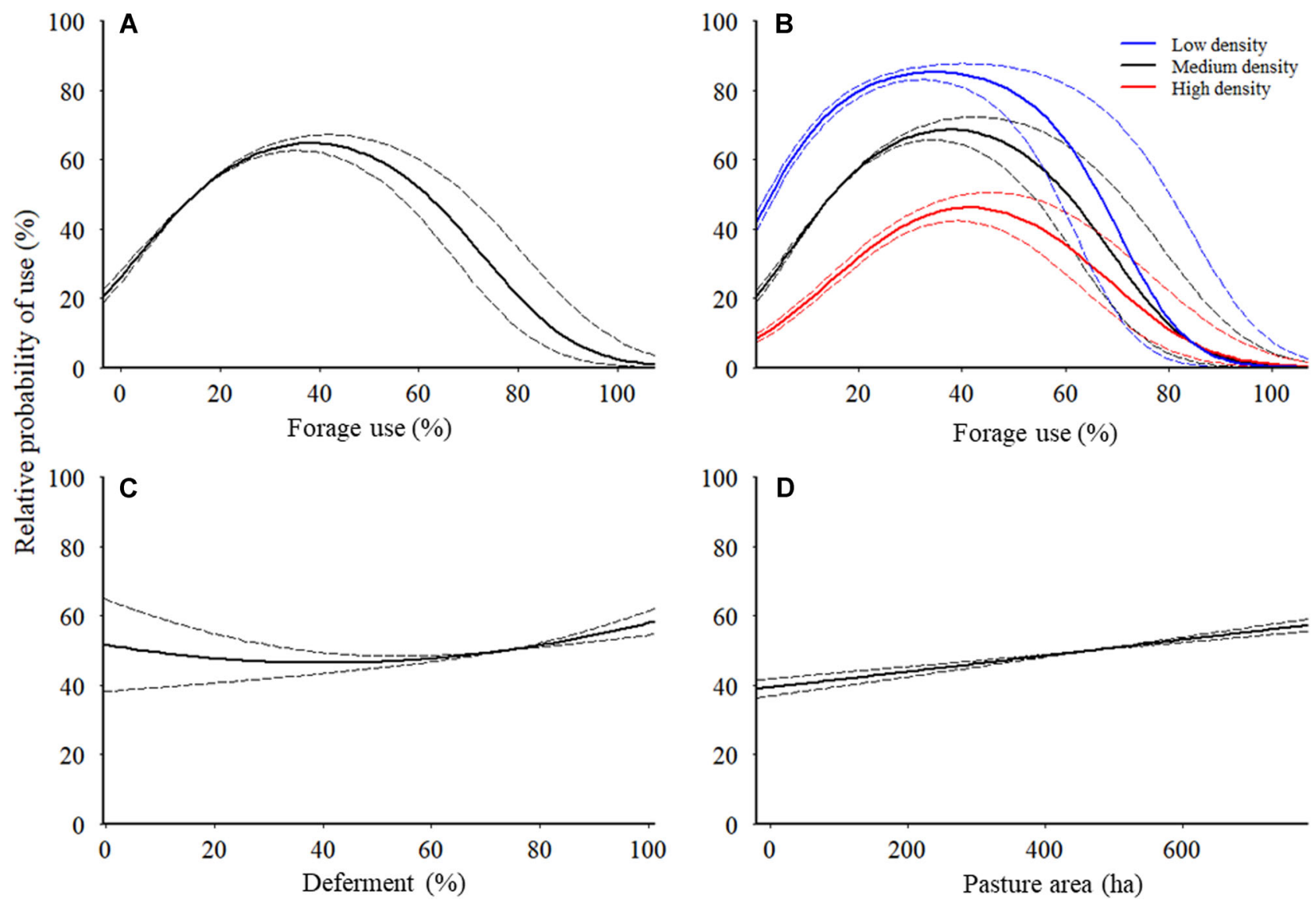

Figure 4. Relative probability of use response curves illustrating nonbreeding habitat selection by female lesser prairie-chickens in relation to A) forage use (\%), B) forage use at 3 levels of stocking density $(\bar{x} \pm 1 \mathrm{SD}$; animal units/ha [AU/ha]; low [0.06 AU/ha], medium [0.13 AU/ha], and high [0.56 AU/ha]), C) deferment (proportion of growing season), and D) pasture area (ha) within monitored grasslands grazed by cattle in western Kansas, USA, 2013-2015. We developed response curves using output from resource selection functions. We calculated forage use assuming a $50 \%$ grazing efficiency (proportion of the allocated forage consumed by livestock). The prediction curves are bounded by $95 \%$ confidence intervals (dashed lines).

distribution process is primarily influenced by stocking density. Cattle perceive variation in forage quality across a pasture and selectively graze accordingly. At high levels of stocking density, competition for high quality forage increases and cattle are forced to graze in lower quality areas
(Barnes et al. 2008). Increased competition for high quality forage associated with high stocking densities leads to greater uniformity of grazing pressure (use of the entire gradient of forage quality), resulting in uniformity in microhabitat structure across a pasture (Fuhlendorf et al. 2006). When

Table 2. Summary of beta coefficients $(\beta)$ and $95 \%$ upper (UCI) and lower (LCI) confidence intervals from top-ranked resource selection functions identified using Akaike's Information Criterion for nonbreeding habitat selection (2013-2016) and nest-site selection (2013-2015) by female lesser prairiechickens within monitored working grasslands in western Kansas, USA, 2013-2016.

\begin{tabular}{|c|c|c|c|c|}
\hline Model set & Variables & $\beta$ & $95 \%$ LCI & $95 \%$ UCI \\
\hline \multirow[t]{2}{*}{ 1) Grazing intensity } & Forage use & 0.6397 & 0.5908 & 0.6885 \\
\hline & Forage use $^{2}$ & -0.1681 & -0.1959 & -0.1404 \\
\hline \multirow[t]{3}{*}{ 2) Pasture area } & Forage use & 0.5739 & 0.5226 & 0.6252 \\
\hline & Forage use $^{2}$ & -0.1504 & -0.1790 & -0.1218 \\
\hline & Pasture area & 0.1546 & 0.1169 & 0.1923 \\
\hline \multirow{5}{*}{ 3) Deferment } & Forage use & 0.7825 & 0.7049 & 0.8600 \\
\hline & Forage use ${ }^{2}$ & -0.1878 & -0.2215 & -0.1542 \\
\hline & Deferment $^{2}$ & 0.0442 & 0.0055 & 0.0830 \\
\hline & Deferment & 0.1594 & 0.1002 & 0.2186 \\
\hline & Forage use $^{2}:$ deferment ${ }^{2}$ & -0.0301 & -0.0650 & 0.0048 \\
\hline \multirow[t]{4}{*}{ 4) Stocking density } & Forage use & 0.8440 & 0.7909 & 0.8971 \\
\hline & Forage use ${ }^{2}$ & -0.2274 & -0.2719 & -0.1828 \\
\hline & Stocking density & -1.0697 & -1.1698 & -0.9696 \\
\hline & Forage use ${ }^{2}$ : stocking density & 0.0331 & 0.0049 & 0.0612 \\
\hline \multirow{3}{*}{ 5) Nest-site selection } & Grazing pressure & 1.0067 & 0.2557 & 1.7577 \\
\hline & Grazing pressure $^{2}$ & -0.3285 & -0.6787 & 0.0216 \\
\hline & Pasture area & 0.3154 & -0.0701 & 0.7009 \\
\hline
\end{tabular}


Table 3. Model ranking of resource selection functions, based on Akaike's Information Criterion corrected for small sample size $\left(\mathrm{AIC}_{c}\right)$, evaluating nest-site selection by lesser prairie-chickens within monitored working grasslands in western Kansas, USA, 2014-2015. We developed model sets to investigate influences of grazing intensity and heterogeneity-based grazing management. Variables in models sets include forage utilization (\% of forage consumed or destroyed), grazing pressure (index of grazing units per area over time; animal unit month [AUM]/ha), pasture area (size of pasture unit; ha), deferment (number of days during the grazing season [Apr-Sep] a pasture unit is void of cattle), and stocking density (number of grazing units per unit area; AU/ha). We include number of parameters $(K)$, deviance (Dev), and Akaike weight $\left(w_{i}\right)$ for each model.

\begin{tabular}{|c|c|c|c|c|}
\hline Model structure & $K$ & Dev & $\Delta \mathrm{AIC}_{c}$ & $w_{i}$ \\
\hline Grazing pressure $^{2}+$ pasture area & 5 & 181.28 & 0.00 & 0.18 \\
\hline Grazing pressure $^{2}$ & 4 & 183.86 & 0.45 & 0.14 \\
\hline Grazing pressure ${ }^{2} \times$ stocking density & 6 & 179.64 & 0.48 & 0.14 \\
\hline Grazing pressure ${ }^{2}+$ deferment & 5 & 182.06 & 0.77 & 0.12 \\
\hline Grazing pressure $^{2} \times$ pasture area & 6 & 180.88 & 1.72 & 0.08 \\
\hline Forage $\mathrm{use}^{2}+$ pasture area & 5 & 183.50 & 2.21 & 0.06 \\
\hline Grazing pressure ${ }^{2} \times$ deferment & 6 & 181.54 & 2.39 & 0.05 \\
\hline Grazing pressure ${ }^{2}+$ stocking density & 5 & 183.84 & 2.56 & 0.05 \\
\hline Forage use ${ }^{2}$ & 4 & 185.96 & 2.56 & 0.05 \\
\hline Pasture area & 3 & 189.58 & 4.08 & 0.02 \\
\hline Forage use ${ }^{2} \times$ pasture area & 6 & 183.50 & 4.35 & 0.02 \\
\hline Forage use ${ }^{2}+$ stocking density & 5 & 185.78 & 4.49 & 0.02 \\
\hline Forage use ${ }^{2}+$ deferment & 5 & 185.84 & 4.55 & 0.02 \\
\hline Forage use ${ }^{2} \times$ deferment & 6 & 185.36 & 6.21 & 0.01 \\
\hline Deferment & 3 & 191.78 & 6.28 & 0.01 \\
\hline Null & 2 & 193.88 & 6.33 & 0.01 \\
\hline Forage use ${ }^{2} \times$ stocking density & 6 & 185.76 & 6.61 & 0.01 \\
\hline Stocking density & 3 & 193.72 & 8.23 & 0.00 \\
\hline
\end{tabular}

stocking densities are held at low to moderate values, the pattern of grazing disturbance across a pasture mimics the pattern of forage quality (Chapman et al. 2007). Subsequently, a gradient of light to heavy grazing disturbance develops as pasture size increases. The gradient in grazing disturbance creates a corresponding gradient of vegetation structure and thus microhabitat heterogeneity. As predicted, results indicated that female lesser prairie-chickens select habitat based on the microhabitat heterogeneity created at lower values of stocking density.

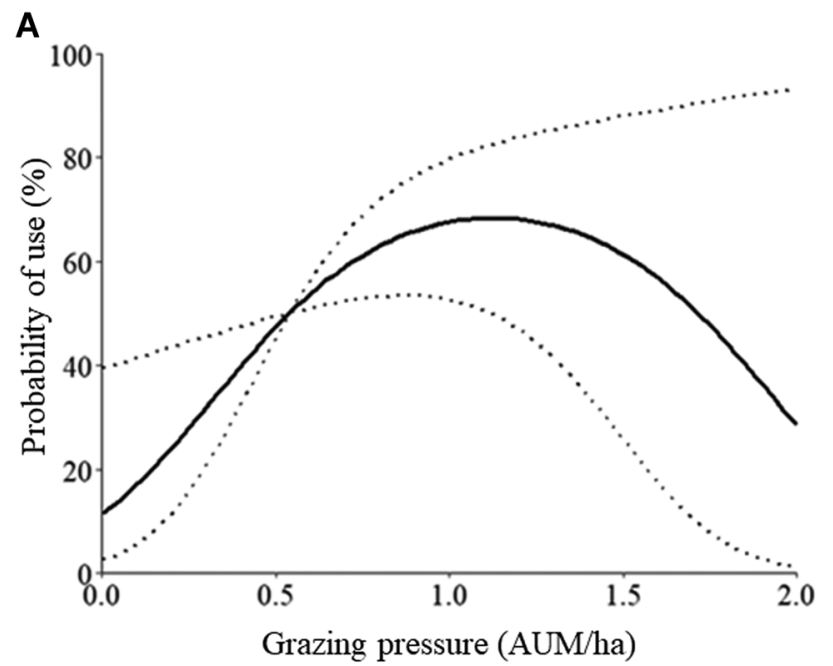

Table 4. Model ranking based on Akaike's Information Criterion corrected for small sample size $\left(\mathrm{AIC}_{c}\right)$ of lesser prairie-chicken nest survival estimation for nests in working grasslands monitored in western Kansas, USA, during 2015. A priori models included variable combinations of date during the nesting season (date), a quadratic function of date (date ${ }^{2}$ ), grazing pressure (animal unit month [AUM]/ha), stocking density (animal unit $[\mathrm{AU}] / \mathrm{ha}$ ), pasture area (ha), forage use (proportion of forage consumed or destroyed), deferment (number of days deferred during the grazing season), and a constant model. We include number of parameters $(K)$, deviance (Dev), and Akaike weight $\left(w_{i}\right)$ for each model.

\begin{tabular}{|c|c|c|c|c|}
\hline Model structure & $K$ & Dev & $\Delta \mathrm{AIC}_{c}$ & $w_{i}$ \\
\hline Date + date $^{2}$ & 3 & 164.62 & 0.00 & 0.16 \\
\hline $\begin{array}{l}\text { Date }+ \text { date }^{2}+\text { grazing pressure }+ \\
\text { stocking density }\end{array}$ & 5 & 161.38 & 0.79 & 0.11 \\
\hline Date + date $^{2}+$ grazing pressure & 4 & 163.62 & 1.02 & 0.10 \\
\hline Date + date $^{2}+$ pasture area & 4 & 163.83 & 1.22 & 0.09 \\
\hline Date + date $^{2}+$ stocking density & 4 & 164.14 & 1.54 & 0.07 \\
\hline Date + date $^{2}+$ forage use & 4 & 164.52 & 1.92 & 0.06 \\
\hline Date + date $^{2}+$ deferment & 4 & 164.55 & 1.94 & 0.06 \\
\hline $\begin{array}{l}\text { Date }+ \text { date }{ }^{2}+\text { grazing pressure }+ \\
\text { pasture area }\end{array}$ & 5 & 162.66 & 2.08 & 0.06 \\
\hline $\begin{array}{l}\text { Date }+ \text { date }{ }^{2}+\text { grazing pressure }+ \\
\text { deferment }\end{array}$ & 5 & 163.30 & 2.72 & 0.04 \\
\hline Null & 1 & 171.76 & 3.12 & 0.03 \\
\hline Date + date $^{2}+$ forage use + pasture area & 5 & 163.77 & 3.19 & 0.03 \\
\hline $\begin{array}{l}\text { Date }+ \text { date }^{2}+\text { forage use }+ \text { stocking } \\
\text { density }\end{array}$ & 5 & 163.90 & 3.31 & 0.03 \\
\hline Date + date $^{2}+$ forage use + deferment & 5 & 164.34 & 3.75 & 0.02 \\
\hline Grazing pressure & 2 & 170.74 & 4.11 & 0.02 \\
\hline Grazing pressure + stocking density & 3 & 168.84 & 4.22 & 0.02 \\
\hline Pasture area & 2 & 171.00 & 4.37 & 0.02 \\
\hline Stocking density & 2 & 171.43 & 4.80 & 0.01 \\
\hline Forage use & 2 & 171.61 & 4.98 & 0.01 \\
\hline Deferment & 2 & 171.70 & 5.06 & 0.01 \\
\hline Grazing pressure + pasture area & 3 & 169.78 & 5.16 & 0.01 \\
\hline Grazing pressure + deferment & 3 & 170.43 & 5.81 & 0.01 \\
\hline Forage use + pasture area & 3 & 170.88 & 6.26 & 0.01 \\
\hline Forage use + stocking density & 3 & 171.13 & 6.51 & 0.01 \\
\hline Forage use + deferment & 3 & 171.42 & 6.80 & 0.01 \\
\hline
\end{tabular}

Previous researchers have assumed that increases in grazing disturbance (i.e., forage use, grazing pressure) result in negative effects on microhabitat quality for lesser prairie-chickens (Hagen et al. 2004, Dahlgren et al. 2016,
B

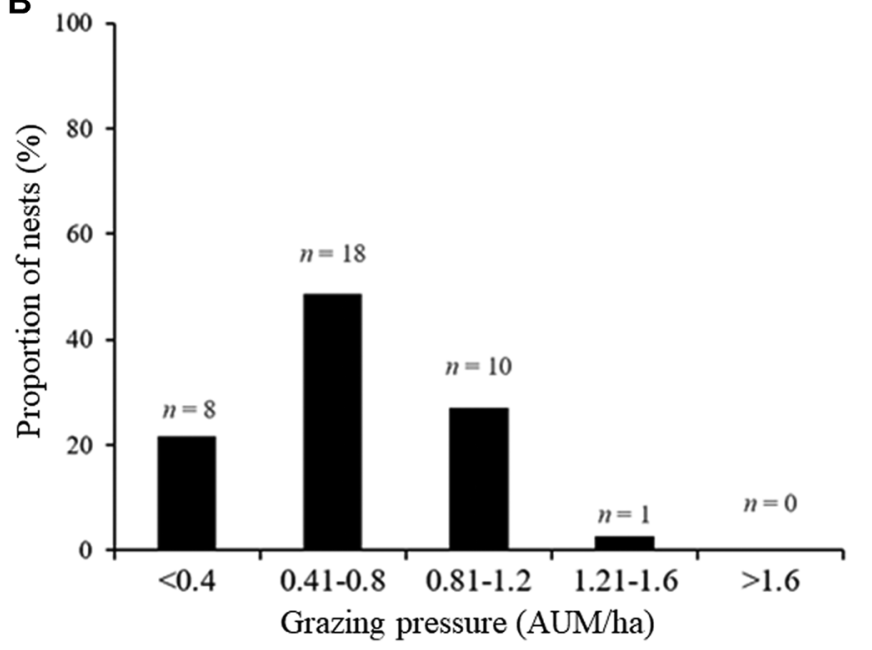

Figure 5. A) Relative probability of use curve (bounded by $95 \% \mathrm{CIs}$ ) describing nest-site selection by female lesser prairie-chickens in relation to grazing pressure (animal units/ha [AU/ha]) during the 2015 nesting season in monitored grasslands in western Kansas, USA. B) Proportions of nest-site locations used to estimate nest-site selection observed within 0.4 animal unit months (AUM)/ha interval bins of grazing pressure estimates. 


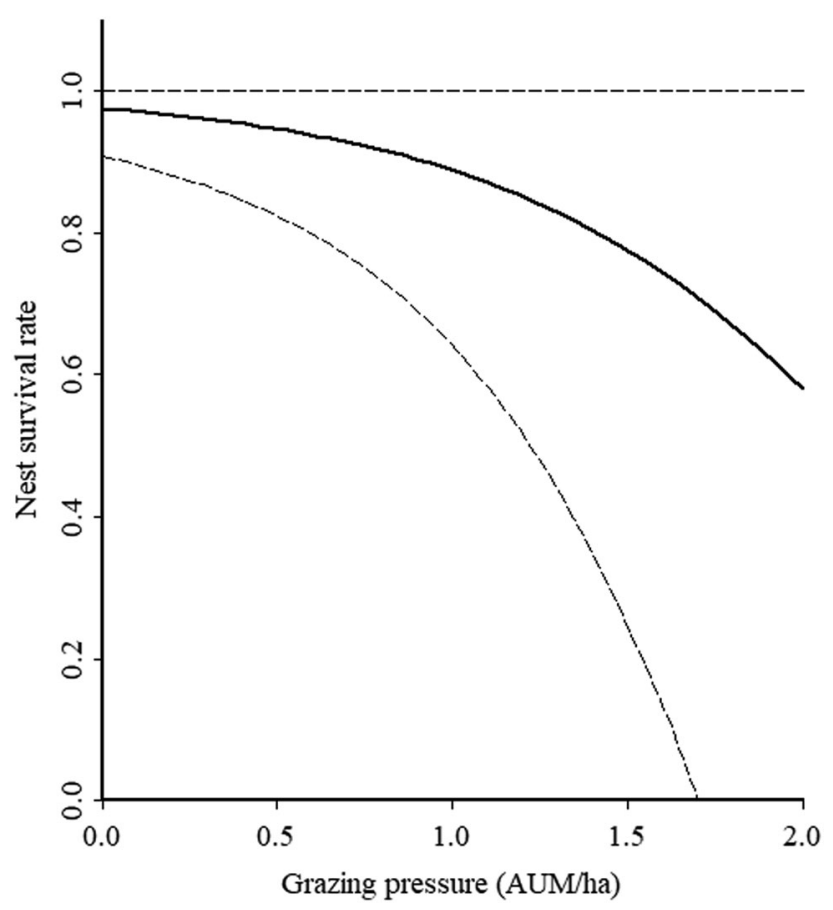

Figure 6. Daily nest survival response curve (bounded by $95 \% \mathrm{CIs}$ ) of lesser prairie-chickens in relation to grazing pressure (animal unit months [AUM]/ha]) in monitored grasslands of western Kansas, USA, 2014-2015. We held stocking density and date ${ }^{2}$ at their mean during modeling. Response curves are enveloped within 95\% confidence intervals (dashed lines).

Hagen and Elmore 2016). We observed a threshold effect on lesser prairie-chicken habitat use in the northern portion of the species' distribution where relative probability of use was maximized near $40 \%$ forage use and steadily decreased at forage use beyond this threshold. These values corroborate prescriptions of forage use values between $30-50 \%$ recommended by Western Association of Fish and Wildlife Agencies in the Lesser Prairie-Chicken Range-Wide Conservation Plan and Natural Resources Conservation Service Lesser Prairie-Chicken Initiative (Van Pelt et al. 2013, Kansas Natural Resources Conservation Service 2014). Effects of forage use likely fluctuate as plant community composition, precipitation, and forage production vary. Thus, average expected forage production within monitored grasslands in our study was $2,639 \mathrm{~kg} / \mathrm{ha}$. Consideration for site-specific conditions (i.e., precipitation,

Table 5. Model ranking for Anderson-Gill models, based on Akaike's Information Criterion corrected for small sample size $\left(\mathrm{AIC}_{c}\right)$, for 5 models identifying the effects of grazing strategies on annual survival of female lesser prairie-chickens within working grasslands monitored in western Kansas, USA, during 2013-2016. A priori models included single-variable models of forage use (proportion of forage consumed or destroyed), grazing pressure (animal unit month [AUM]/ha), stocking density (animal unit $[\mathrm{AU}] / \mathrm{ha})$, and pasture area (ha). We include number of parameters $(K)$, deviance (Dev), and Akaike weight $\left(w_{i}\right)$ for each model.

\begin{tabular}{lcccc}
\hline Model structure & $\boldsymbol{K}$ & $\mathbf{D e v}$ & $\boldsymbol{\Delta} \mathbf{A I C}_{\boldsymbol{c}}$ & $\boldsymbol{w}_{\boldsymbol{i}}$ \\
\hline Null & 1 & 73.37 & 0.00 & 0.36 \\
Stocking density & 2 & 74.77 & 1.40 & 0.18 \\
Grazing pressure & 2 & 74.79 & 1.42 & 0.15 \\
Forage use & 2 & 75.18 & 1.81 & 0.15 \\
Pasture area & 2 & 75.37 & 2.00 & 0.13 \\
\hline
\end{tabular}

plant community composition, forage production potential, historical management) will be essential for prescribing forage use values to achieve desired vegetation structural goals.

Previous research indicates that lesser prairie-chicken nestsite placement is characterized by the tendency of females to place nests in areas of greater grass cover, litter cover, and visual obstruction with relatively lower area of bare ground (Davis 2009, Hagen et al. 2013, Grisham et al. 2014, Haukos and Zavaleta 2016, Lautenbach et al. 2019). Nestsite selection had the greatest relative probability of occurrence at forage use values of $15-20 \%$ and declined rapidly as forage use increased past 20\%. This result concurred with previously established patterns of nest-site selection by lesser prairie-chickens and importance of lightly disturbed habitat (Fritts et al. 2016, Haukos and Zavaleta 2016).

Baseline responses of habitat selection by lesser prairiechickens to grazing disturbance provided insights into effects of heterogeneity-based grazing management. Variation of environmental characteristics such as soils, plant communities, and microhabitat structure is positively correlated with spatial scale (Wiens 1989, 2000). Thus, there is likely an inherent positive relationship between habitat heterogeneity and increasing pasture size within our study sites. Intuitively, an increase in pasture size also increased the probability of a required lesser prairie-chicken female resource (i.e., leks, nest habitat, brood habitat, winter cover) being present. Despite the increased probability of lesser prairie-chicken microhabitat presence at larger scales, it is unlikely that the relationship between pasture area and presence of quality habitat is independently creating the increased probability of use by female lesser prairie-chickens as pasture area increases. Our results combined with established concepts of grazing ecology indicate that grazing management strategies associated with larger pasture areas, such as stocking density, may be a more significant influence on microhabitat heterogeneity and lesser prairie-chicken occurrence than pasture size alone.

There was a threshold effect of deferment where probability of use increased at low and high values of deferment. We hypothesize that site-specific variation is influencing this pattern. For example, long periods of rest or deferment are likely beneficial for grasslands that exhibit relatively low potential for the production of nesting habitat. Alternatively, in grasslands exhibiting high potential for biomass production, longer grazing periods may be required to achieve desired habitat outcomes. Additional investigations focusing on the influence of deferment with consideration for regional variation is required to understand this pattern.

We did not observe a definitive pattern of lesser prairiechicken adult survival and nest success in response to heterogeneity-based grazing strategies as we did with patterns of habitat selection. Our data suggested, however, that increasing grazing disturbance during the year previous to nest initiation may have negative influence on lesser prairiechicken nest success. This pattern was contrary to grazing studies on other prairie grouse that reported equivocal effects 
(Fritts et al. 2016, Smith et al. 2018, Milligan et al. 2020a). Although in some cases, grazing indirectly affected nesting success by providing (or removing) adequate vegetation visual obstruction. Increasing female survival during the breeding season, combined with improving recruitment is often a priority for lesser prairie-chicken population management (Hagen et al. 2009, 2013). Development of ranchscale heterogeneity (among pastures) may mitigate effects of grazing disturbance by providing pastures with quality nesting or brood-rearing microhabitat (Fritts et al. 2018). For example, a manager could prioritize nest success within certain pastures by applying specific grazing prescriptions. In our study systems, models suggest pastures with an annual grazing pressure of $0.5 \mathrm{AUM} /$ ha would result in nest success of approximately $61 \%$ based on expected available forage. Nest success at this level would be above average and representative of a stable or growing population (Hagen et al. 2013). Additionally, areas managed for greater nest success may also provide habitat that favors adult female survival during the breeding season because significant portions of adult female mortality occurs during nesting and survival is positively correlated with greater values of overhead cover (Hagen et al. 2007). Other pastures could then be grazed at levels convenient for livestock production or brood habitat. Adaptive grazing may promote heterogeneity among pastures following a deferred-rotation grazing strategy (Merrill 1954) and ensure the presence of quality habitat as weather and climate amplify the negative effects of forage use on vegetation structure (Ross et al. 2016a, b; Fritts et al. 2018). At finer scales (i.e., within pasture), success of heterogeneity-based grazing prescriptions may hinge on the development of interspersion of nesting, brooding, and nonbreeding habitats (Hagen et al. 2009, Gehrt et al. 2020).

Applying site-specific grazing prescription may also be beneficial for overall participation in lesser prairie-chicken conservation strategies by private landowners. If recommendations for grazing management inhibit profitability, they will not be relevant in providing certainty for this imperiled species. Long-term grazing extension research in the region of our study suggests that moderate stocking rates (i.e., $45-50 \%$ forage use) optimize forage production and livestock gains (Launchbaugh 1957). Recent market data applied to the same long-term research suggest that moderate stocking rates also maximize profitability (K. R. Harmoney, Kansas State University, personal communication).

Although effective grazing prescriptions are site-specific, our results indicate that some grazing is beneficial for lesser prairie-chickens, whereas intensive grazing can be harmful or cause avoidance of potential habitat. Our results offer an alternative for creating heterogeneous habitat for female lesser prairie-chickens through grazing management when prescribed fire may not be feasible. Heterogeneity-based grazing management strategies may not be optimum for some working grasslands where plant community composition and relatively low precipitation may not promote lesser prairie-chicken nest microhabitat under the influence of even light grazing disturbances. The prevalence of shortgrass prairie dominated by buffalo grass and blue grama in the Short-Grass Prairie/CRP Mosaic Ecoregion may require a rest-rotation grazing management scheme including season-long rest of pastures to create beneficial microhabitat for nesting (e.g., $100 \%$ visual obstruction $>20 \mathrm{~cm}$; Lautenbach et al. 2019). Only with the addition of mid- and tall grasses through the CRP were populations of lesser prairie-chickens sustainable in this ecoregion (Sullins et al. 2018). Therefore, a moderate grazing disturbance at the landscape scale is likely within the range of forage use goals adequate for maintaining lesser prairie-chicken habitat throughout much of the species' range.

\section{MANAGEMENT IMPLICATIONS}

Some of the largest contemporary recorded lesser prairiechicken population densities were recorded within our study sites on landscapes characterized by long-term grazing management. Therefore, our findings are primarily in the context of maintaining and improving existing occupied habitat. Although other factors (e.g., energy development, habitat fragmentation) may be involved, lesser prairiechickens were not present in detectable densities on neighboring sites that used more intensive grazing strategies. In regions with similar plant species composition and environmental characteristics to our study sites, heterogeneity-based grazing management may benefit lesser prairie-chickens by establishing strategies that include large pastures, low stock densities, and relatively long grazing periods. Grazing disturbance would best be targeted at $10-25 \%$ forage use in areas capable of producing nesting structure, but we encourage variation in forage use (15-50\%) to meet heterogeneity needs among pastures. If the potential for nesting vegetation structure is limited or inconsistent because of the plant community or precipitation, maintenance of available nesting habitat may be possible through targeted deferment or forage use $<15 \%$. Management considerations to increase quality of lesser prairie-chicken habitat might not be as applicable to sites exhibiting less-favorable conditions resulting from the deleterious effects of long-term, heavy, continuous grazing or recent intensive drought events. More likely, our findings are better suited to sites exhibiting site potential and soil qualities conducive for supporting quality lesser prairiechicken habitat.

\section{ACKNOWLEDGMENTS}

The contents and opinions herein do not necessarily reflect the views or policies of the United States Fish and Wildlife Service or the Kansas Department of Wildlife, Parks and Tourism. Any use of trade, firm, or product names is for descriptive purposes only and does not imply endorsement by the United States Government. We thank K. E. Sexson, J. L. Kramer, M. W. Mitchener, D. K. Dahlgren, J. A. Prendergast, K. A. Fricke, D. J. Kraft, R. W. Tacha, P. G. Kramos, A. A. Flanders, and B. S. T. Hyberg for their assistance with the project. We thank 2 anonymous reviewers for reviewing earlier versions of this manuscript. Research was funded by the USDA, Natural Resources Conservation Service, Lesser Prairie-Chicken Initiative; 
Kansas Department of Wildlife, Parks, and Tourism (Federal Assistance Grant KS W-73-R-3); The Kingsbury Family Foundation; and USDA Farm Services CRP Monitoring, Assessment, and Evaluation (12-IA-MRE CRP TA7, KSCFWRU RWO 62).

\section{LITERATURE CITED}

Allred, B. W., S. D. Fuhlendorf, and R. G. Hamilton. 2011. The role of herbivores in Great Plains conservation: comparative ecology of bison and cattle. Ecosphere 2:26.

Anderson, D. R., and K. P. Burnham. 2002. Avoiding pitfalls when using information-theoretic methods. Journal of Wildlife Management 66:912-918.

Andersen, P. K., and R. D. Gill. 1982. Cox's regression model for counting processes: a large sample study. Annals of Statistics 10:1100-1120.

Augustine, D. J., and J. D. Derner. 2015. Patch-burn grazing management, vegetation heterogeneity, and avian responses in a semi-arid grassland. Journal of Wildlife Management 79:927-936.

Barnes, M. K., B. E. Norton, M. Maeno, and J. C. Malechek. 2008. Paddock size and stocking density affect spatial heterogeneity of grazing. Rangeland Ecology \& Management 61:380-388.

Bates, D., M. Machler, B. M. Bolker, and S. C. Walker. 2015. Fitting linear mixed-effects models using lme4. Journal of Statistical Software 67:1-48.

Beyer, H. L. 2012. Geospatial Modelling Environment (version 0.7.3.0). $<$ http://www.spatialecology.com/gme>. Accessed 10 Mar 2020.

Boyce, M. S., P. R. Vernier, S. E. Nielsen, and F. K. Schmiegelow. 2002. Evaluating resource selection functions. Ecological Modelling 157:281-300.

Chapman, D. F., A. J. Parsons, G. P. Cosgrove, D. J. Barker, D. M. Marotti, K. J. Venning, S. M. Rutter, J. Hill, and A. N. Thompson. 2007. Impacts of spatial patterns in pasture on animal grazing behavior, intake, and performance. Crop Science 47:399-415.

Cochran, W. W., and R. D. Lord, Jr. 1963. A radio-tracking system for wild animals. Journal of Wildlife Management 27:9-24.

Dahlgren, D., R. Rodgers, R. Elmore, and M. Bain. 2016. Grasslands of western Kansas north of the Arkansas River. Pages 259-280 in D. Haukos and C. Boal, editors. Ecology and management of lesser prairie-chickens. CRC Press, Boca Raton, Florida, USA.

Daubenmire, R. 1959. A canopy-coverage method of vegetational analysis. Northwest Science 33:43-64.

Davis, D. M. 2009. Nesting ecology and reproductive success of lesser prairie-chickens in shinnery oak-dominated rangelands. Wilson Journal of Ornithology 121:322-327.

Derner, J. D., W. K. Lauenroth, P. Stapp, and D. J. Augustine. 2009. Livestock as ecosystem engineers for grassland bird habitat in the western Great Plains of North America. Rangeland Ecology \& Management 62:111-118.

Dinkins, J. B., M. R. Conover, C. P. Kirol, J. L. Beck, and S. N. Frey. 2014. Greater sage-grouse (Centrocercus urophasianus) female survival: effects of raptors, anthropogenic and landscape features, and female survival. Canadian Journal of Zoology 92:319-330.

Dzialak, M. R., C. V. Olson, S. M. Harju, S. L. Webb, J. P. Mudd, J. B. Winstead, and L. Hayden-Wing. 2011. Identifying and prioritizing greater sage-grouse nesting and brood rearing habitat for conservation in human-modified landscapes. PLoS ONE 6:e26273.

Earl, J. E., S. D. Fuhlendorf, D. Haukos, A. M. Tanner, D. Elmore, and S. A. Carleton. 2016. Characteristics of lesser prairie-chicken (Tympanuchus pallidicinctus) long-distance movements across their distribution. Ecosphere 7:e01441.

Fleischner, T. L. 1994. Ecological costs of livestock grazing in western North America. Conservation Biology 8:629-644.

Fox, J., and S. Weisberg. 2011. Cox proportional-hazards regression for survival data in R. Pages 1-20 in J. Fox and S. Weisberg, editors. An appendix to an $\mathrm{R}$ companion to applied regression. Second edition. SAGE Publications, Washington, D.C., USA.

Fritts, S. F., B. A. Grisham, D. A. Haukos, C. W. Boal, M. A. Patten, D. H. Wolfe, C. E. Dixon, R. D. Cox, and W. R. Heck. 2016. Longterm evaluation of lesser prairie-chicken nest ecology in response to grassland restoration at two spatial scales. Journal of Wildlife Management 80:527-539.

Fritts, S. R., B. A. Grisham, R. D. Cox, C. W. Boal, D. A. Haukos, P. McDaniel, C. A. Hagen, and D. U. Greene. 2018. Interactive effects of severe drought and grazing on the life history cycle of a bioindicator species. Ecology and Evolution 8:9550-9562.

Fuhlendorf, S., and D. Engle. 2001. Restoring heterogeneity on rangelands: ecosystem management based on evolutionary grazing patterns. BioScience 51:625-632.

Fuhlendorf, S., H. Wade, D. M. Engle, R. Hamilton, C. Davis, and D. Leslie. 2006. Should heterogeneity be the basis for conservation? Grassland bird response to fire and grazing. Ecological Applications 16:1706-1716.

Fuhlendorf, S. D., D. M. Engle, J. D. Kerby, and R. Hamilton. 2009. Pyric herbivory: rewilding landscapes through the recoupling of fire and grazing. Conservation Biology 23:588-598.

Gehrt, J. M., D. S. Sullins, and D. A. Haukos. 2020. Looking at the bigger picture: how abundance of nesting and brooding habitat influences lek-site selection by lesser prairie-chickens. American Midland Naturalist 183:52-77.

Giesen, K. M. 1994. Movements and nesting habitat of lesser prairiechicken hens in Colorado. Southwestern Naturalist 39:96-98.

Gillies, C. S., M. Hebblewhite, S. E. Nielsen, M. A. Krawchuk, C. L. Aldridge, J. L. Frair, D. J. Saher, C. E. Stevens, and C. L. Jerde. 2006. Application of random effects to the study of resource selection by animals. Journal of Animal Ecology 75:887-898.

Goldewijk, K. K. 2001. Estimating global land use change over the past 300 years: the HYDE database. Global Biogeochemical Cycles 15:417-433.

Grisham, B. A., P. K. Borsdorf, C. W. Boal, and K. K. Boydston. 2014. Nesting ecology and nest survival of lesser prairie-chickens on the Southern High Plains of Texas. Journal of Wildlife Management 78:857-866.

Hagen, C. A., and R. D. Elmore. 2016. Synthesis, conclusions, and a path forward. Pages 345-352 in D. Haukos and C. Boal, editors. Ecology and management of lesser prairie-chickens. CRC Press, Boca Raton, Florida, USA.

Hagen, C. A., E. O. Garton, G. Beauprez, B. S. Cooper, K. A. Fricke, and B. Simpson. 2017. Lesser prairie-chicken population forecasts and extinction risks: an evaluation 5 years post-catastrophic drought. Wildlife Society Bulletin 41:624-638.

Hagen, C. A., B. A. Grisham, C. W. Boal, and D. A. Haukos. 2013. A meta-analysis of lesser prairie-chicken nesting and brood-rearing habitats: implications for habitat management. Wildlife Society Bulletin 37:750-758.

Hagen, C. A., B. E. Jamison, K. M. Giesen, and T. Z. Riley. 2004. Guidelines for managing lesser prairie-chicken populations and their habitats. Wildlife Society Bulletin 32:69-82.

Hagen, C. A., J. C. Pitman, B. K. Sandercock, R. J. Robel, and R. D. Applegate. 2007. Age-specific survival and probable causes of mortality in female lesser-prairie chickens. Journal of Wildlife Management 71:518-525.

Hagen, C. A., B. K. Sandercock, J. C. Pitman, R. J. Robel, and R. D. Applegate. 2009. Spatial variation in lesser prairie-chicken demography: a sensitivity analysis of population dynamics and management alternatives. Journal of Wildlife Management 73:1325-1332.

Hart, R. H., M. J. Samuel, P. S. Test, and M. A. Smith. 1988. Cattle, vegetation, and economic responses to grazing systems and grazing pressure. Journal of Range Management 41:282-286.

Haukos, D. A., L. M. Smith, and G. S. Broda. 1990. Spring trapping of lesser prairie-chickens. Journal of Field Ornithology 61:20-25.

Haukos, D. A., and J. C. Zavaleta. 2016. Habitat. Pages 99-132 in D. Haukos and C. Boal, editors. Ecology and conservation of lesser prairie-chickens. CRC Press, Boca Raton, Florida, USA.

Hoekstra, J. M., T. M. Boucher, T. H. Ricketts, and C. Roberts. 2005. Confronting a biome crisis: global disparities of habitat loss and protection. Ecology Letters 8:23-29.

Holechek, J. L., R. D. Pieper, and C. H. Herbel. 1989. Range management: principles and practices. Prentice-Hall, Englewood Cliffs, New Jersey, USA.

Hovick, T. J., R. D. Elmore, and S. D. Fuhlendorf. 2014. Structural heterogeneity increases diversity of non-breeding grassland birds. Ecosphere 5:62.

Hovick, T. J., R. D. Elmore, S. D. Fuhlendorf, D. M. Engle, and R. G. Hamilton. 2015. Spatial heterogeneity increases diversity and stability in grassland bird communities. Ecological Applications 25:662-672.

Ihaka, R., and R. Gentleman. 1996. R: a language for data analysis and graphics. Journal of Computational and Graphical Statistics 5:299-314.

Kansas Natural Resources Conservation Service. 2014. Identifying and creating lesser and greater prairie-chicken habitat. Kansas Range 
Technical Note, KS-9, Natural Resources Conservation Service, Saline, Kansas, USA. https://www.nrcs.usda.gov/wps/portal/nrcs/detail/ks/ people/employees/?cid=nrcs142p2_033405. Accessed 27 Sep 2016.

Kaplan, E. L., and P. Meier. 1958. Nonparametric estimation from incomplete observations. Journal of the American Statistical Association 53:457-481.

Knapp, A. K., J. M. Blair, J. M. Briggs, S. L. Collins, and D. C. Hartnett. 1999. The keystone role of bison in North American tallgrass prairiebison increase habitat heterogeneity and alter a broad array of plant, community, and ecosystem processes. Bioscience 49:39-50.

Knopf, F. L. 1994. Avian assemblages on altered grasslands. Studies in Avian Biology 15:247-257.

Launchbaugh, J. L. 1957. The effect of stocking rate on cattle gains and on native shortgrass vegetation in west central Kansas. Bulletin 394, Kansas Agricultural Experiment Station, Hays, USA.

Lautenbach, J. M. 2015. Lesser prairie-chicken reproductive success, habitat selection, and response to trees. Thesis, Kansas State University, Manhattan, USA.

Lautenbach, J. M., D. A. Haukos, D. S. Sullins, C. A. Hagen, J. D. Lautenbach, J. C. Pitman, R. T. Plumb, S. G. Robinson, and J. D. Kraft. 2019. Northern exposure: factors influencing nesting ecology of lesser prairie-chickens in Kansas and Colorado. Journal of Wildlife Management 83:205-215.

Manly, B. F. J., L. L. McDonald, D. L. Thomas, T. L. McDonald, and W. P. Erickson. 2002. Resource selection by animals: statistical design and analysis for field studies. Second edition. Kluwer Academic Publishers, Dordrecht, Netherlands.

McDonald, L., G. Beauprez, G. Gardner, J. Griswold, C. Hagen, F. Hornsby, D. Klute, S. Kyle, J. Pitman, and T. Rintz. 2014. Range-wide population size of the lesser prairie-chicken: 2012 and 2013. Wildlife Society Bulletin 38:536-546.

McNew, L. B., A. J. Gregory, S. M. Wisely, and B. K. Sandercock. 2009. Estimating the stage of incubation for nests of greater prairie-chickens using egg flotation: a float curve for grousers. Newsletter of the Grouse Group, Grouse News 38:12-14.

Merrill, L. B. 1954. A variation of deferred rotation grazing for use under southwest range conditions. Journal of Range Management $7: 152-154$.

Milchunas, D. G., O. E. Sala, and W. Lauenroth. 1988. A generalized model of the effects of grazing by large herbivores on grassland community structure. American Naturalist 132:87-106.

Milligan, M. C., L. I. Berkeley, and L. B. McNew. 2020a. Effects of rangeland management on the nesting ecology of sharp-tailed grouse. Rangeland Ecology \& Management 73:128-137.

Milligan, M. C., L. I. Berkeley, and L. B. McNew. 2020b. Habitat selection of female sharp-tailed grouse in grasslands managed for livestock production. PLoS ONE 15:e0233756.

Milligan, M. C., L. I. Berkeley, and L. B. McNew. 2020c. Survival of sharp-tailed grouse under variable livestock grazing management. Journal of Wildlife Management 84:1296-1305.

Pavlacky, D. C., B. B. Woiderski, R. A. Sparks, A. Van Boer, and A. W. Green. 2019. Effectiveness monitoring of the lesser prairie-chicken initiative and conservation reserve program for managing the biodiversity and population size of grassland birds. Technical Report \# LPCI-16-02, Bird Conservancy of the Rockies, Fort Collins, Colorado, USA.

Pitman, J. C., C. A. Hagen, R. J. Robel, T. M. Loughin, and R. D. Applegate. 2005. Location and success of lesser prairie-chicken nests in relation to vegetation and human disturbance. Journal of Wildlife Management 69:1259-1269.

Robel, R. J., J. N. Briggs, A. D. Dayton, and L. C. Hulbert. 1970. Relationships between visual obstruction measurements and weight of grassland vegetation. Journal of Range Management 23:295-297.

Robinson, S. G., D. A. Haukos, R. T. Plumb, J. D. Kraft, D. S. Sullins, J. M. Lautenbach, J. D. Lautenbach, B. K. Sandercock, C. A. Hagen, A. Bartuszevige, et al. 2018. Effects of landscape characteristics on annual survival of lesser prairie-chickens. American Midland Naturalist 180:66-86.

Ross, B. E., D. Haukos, C. Hagen, and J. Pitman. 2016a. The relative contribution of climate to changes in lesser prairie-chicken abundance. Ecosphere 7(6): 01323.

Ross, B. E., D. Haukos, C. Hagen, and J. Pitman. 2016b. Landscape composition creates a threshold influencing lesser prairie-chicken population resilience to extreme drought. Global Ecology and Conservation 6:179-188.

Samson, F. B., F. L. Knopf, and W. R. Ostlie. 2004. Great Plains ecosystems: past, present, and future. Wildlife Society Bulletin 32:6-15.

Silvy, N. J., M. E. Morrow, E. Shanley, and R. D. Slack. 1990. An improved drop net for capturing wildlife. Proceedings of the Southeastern Association of Fish and Wildlife Agencies 44:374-378.

Smith, J. T., J. D. Tack, L. I. Berkeley, M. Szczypinski, and D. E. Naugle. 2018. Effects of livestock grazing on nesting sage-grouse in central Montana. Journal of Wildlife Management 82:1503-1515.

Sullins, D. S., J. D. Kraft, D. A. Haukos, S. G. Robinson, J. Reitz, R. T. Plumb, J. M. Lautenbach, J. D. Lautenbach, B. K. Sandercock, and C. Hagen. 2018. Demographic consequences of Conservation Reserve Program grasslands for lesser prairie-chickens. Journal of Wildlife Management 82:1617-1632.

Taylor, C. A., Jr. 2005. Prescribed burning cooperatives: empowering and equipping ranchers to manage rangelands. Rangelands 27:18-23.

United States Department of Agriculture [USDA]. 2013. Interagency ecological site handbook for rangelands. USDA, Washington, D.C., USA.

Van Pelt, W. E., S. Kyle, J. Pitman, D. Klute, G. Beauprez, D. Schoeling, A. Janus, and J. Haufler. 2013. The lesser prairie-chicken range-wide conservation plan. Western Association of Fish and Wildlife Agencies, Cheyenne, Wyoming, USA.

White, G. C., and K. P. Burnham. 1999. Program MARK: survival estimation from populations of marked animals. Bird Study 46:S120-S139.

Wiens, J. A. 1989. Spatial scaling in ecology. Functional Ecology 3:385-97.

Wiens, J. A. 2000. Ecological heterogeneity: an ontogeny of concepts and approaches. Pages 9-31 in M. J. Hutchings, E. A. John, and A. J. A. Stewart, editors. Ecological consequences of environmental heterogeneity. Blackwell Science, Oxford, England, United Kingdom.

Winder, V. L., L. B. McNew, J. C. Pitman, and B. K. Sandercock. 2016. Space use of female greater prairie-chickens in response to fire and grazing interactions. Rangeland Ecology \& Management 70:165-174.

Winder, V. L., L. B. McNew, J. C. Pitman, and B. K. Sandercock. 2018. Effects of rangeland management on survival of female greater prairiechickens. Journal of Wildlife Management 82:113-122.

Associate Editor: Anthony Roberts.

\section{SUPPORTING INFORMATION}

Additional supporting information may be found in the online version of this article at the publisher's website. 